\title{
Introducing compassion-focused therapy
}

\section{Paul Gilbert}

\begin{abstract}
SUMMARY
Shame and self-criticism are transdiagnostic problems. People who experience them may struggle to feel relieved, reassured or safe. Research suggests that a specialised affect regulation system (or systems) underpins feelings of reassurance, safeness and well-being. It is believed to have evolved with attachment systems and, in particular, the ability to register and respond with calming and a sense of well-being to being cared for. In compassionfocused therapy it is hypothesised that this affect regulation system is poorly accessible in people with high shame and self-criticism, in whom the 'threat' affect regulation system dominates orientation to their inner and outer worlds. Compassion-focused therapy is an integrated and multimodal approach that draws from evolutionary, social, developmental and Buddhist psychology, and neuroscience. One of its key concerns is to use compassionate mind training to help people develop and work with experiences of inner warmth, safeness and soothing, via compassion and self-compassion.
\end{abstract}

\section{DECLARATION OF INTEREST}

None.

The healing properties of compassion have been written about for centuries. The Dalai Lama often stresses that if you want others to be happy - focus on compassion; if you want to be happy yourself - focus on compassion (Dalai Lama 1995, 2001). Although all clinicians agree that compassion is central to the doctor-patient and therapist-client relationship, recently the components of compassion have been looked at through the lens of Western psychological science and research (Gilbert 2000, 2005a, 2009; Davidson 2002; Neff 2003a,b). Compassion can be thought of as a skill that one can train in, with increasing evidence that focusing on and practising compassion can influence neurophysiological and immune systems (Davidson 2003; Lutz 2008). Compassion-focused therapy refers to the underpinning theory and process of applying a compassion model to psychotherapy. Compassionate mind training refers to specific activities designed to develop compassionate attributes and skills, particularly those that influence affect regulation. Compassion-focused therapy adopts the philosophy that our understanding of psychological and neurophysiological processes is developing at such a rapid pace that we are now moving beyond 'schools of psychotherapy' towards a more integrated, biopsychosocial science of psychotherapy (Gilbert 2009).

\section{Clinical focus}

Compassion-focused therapy and compassionate mind training arose from a number of observations. First, people with high levels of shame and selfcriticism can have enormous difficulty in being kind to themselves, feeling self-warmth or being self-compassionate.

Second, it has long been known that problems of shame and self-criticism are often rooted in histories of abuse, bullying, high expressed emotion in the family, neglect and/or lack of affection (Kaufman 1989; Andrews 1998; Schore 1998). Individuals subjected to early experiences of this type can become highly sensitive to threats of rejection or criticism from the outside world and can quickly become self-attacking: they experience both their external and internal worlds as easily turning hostile.

Third, it has been recognised that working with shame and self-criticism requires a therapeutic focus on memories of such early experiences (Kaufman 1989; Schore 1998; Brewin 2003, 2006; Gilbert 2005b). This work can overlap substantially with the therapeutic interventions developed for trauma (Lee 2005; Ogden 2006; Van der Hart 2006; Wheatley 2007).

And fourth, there are clients who engage with the cognitive and behavioural tasks of a therapy, and become skilled at generating (say) alternatives for their negative thoughts and beliefs, but who still do poorly in therapy (Rector 2000). They are likely to say, 'I understand the logic of my alternative thinking but it doesn't really help me feel much better' or 'I know I'm not to blame for the abuse but I still feel that I am'. A key element of compassionfocused therapy is related to the observation that individuals prone to high levels of shame and self-criticism can find it very difficult to generate feelings of cosntentment, safeness or warmth in their relationships with others and themselves.
Paul Gilbert is Professor of Clinical Psychology at the University of Derby and consultant psychologist at Derbyshire Mental Health Services NHS Trust. He is a Fellow of the British Psychological Society and has been actively researching shame-related processes in mood disorders and compassion as a focus for therapeutic interventions. He is currently seeking research monies for appropriate trials.

Correspondence Professor Paul Gilbert, Mental Health Research Unit, Kingsway Hospital, Derby DE22 3LZ, UK. E-mail: p.gilbert@ derby.ac.uk 


\section{Evolution and the neurosciences}

One way of approaching this problem is to focus on the evolved functions that underpin certain types of feeling and styles of social relating (Gilbert 1989, 2005a, 2007, 2009). What are the affect systems that enable us to feel reassured, content and safe, or to register human warmth? Research into the neurophysiology of emotion suggests that we can distinguish at least three types of emotion regulation system (Depue 2005): threat and protection systems; drive, resource-seeking and excitement systems; and contentment, soothing and safeness systems. I will explore each of these in turn and their relationship to compassion-focused therapy. These are not by any means the only way our emotional regulation system can be mapped and conceptualised, and they can be subdivided in various ways (Panksepp 1998), but they offer a useful heuristic for clinical thinking. A simple depiction of their interaction is given in Fig. 1.

\section{Threat and protection}

All living things have evolved with basic threatdetection and protection systems (Box 1). The neurophysiology of this system in humans is increasingly well understood (LeDoux 1998; Panksepp 1998). Its function is to notice threats quickly (through attention-focusing and attentionbiasing) and then give us bursts of feeling such as anxiety, anger or disgust. These feelings ripple through our bodies, alerting and urging us to take action to do something about the threat - to protect ourselves. The behavioural outputs include fight, flight and submission (Marks 1987; Gilbert 2001). The genetic and synaptic regulation of serotonin plays a role in the functioning of the 'threat protection system' (Caspi 2006). Partly because the system is programmed in favour of 'better safe than sorry' (Gilbert 1998) it is easily conditioned (Rosen 1998) and is the source of many aspects of psychopathology.

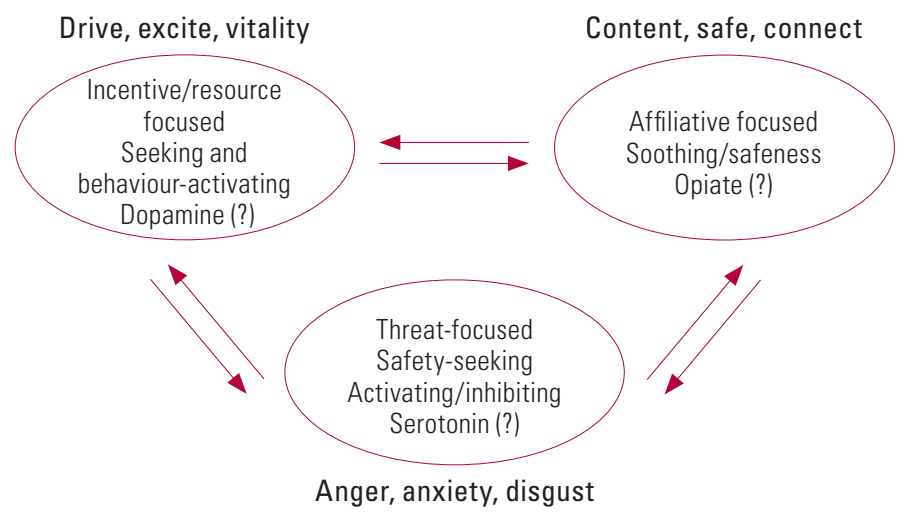

BOX 1 Threat protection systems

- All living things have evolved threat-detection and protection systems

- Stimuli impinging on organisms must be checked out for potential threat

- Mammalian defences include a menu of emotions (e.g., anger, anxiety, disgust), behaviours (e.g., fight, flight, freeze, submission) and cognitive biases (e.g. 'better safe than sorry', 'jumping to conclusions')

- Threat protection systems have evolved to be attuned to certain kinds of threats and operate a better safe than sorry policy

- Sensitivity and response to specific threats are the result of an interaction between genes and learning

- Response options within the threat protection system can conflict, creating confusion

- Brain states choreographed from the threat protection system can bias other processing systems

- Over- and underdevelopment of sensitivities in threatprotection underpin many psychopathologies

The smooth operation of the threat protection system may be difficult, because, for example, many of its response options conflict with each other. It is difficult to engage in both fight and flight behaviour at the same time, and submissive behaviour may involve staying put, being passive and inhibiting both fight and flight. In compassionfocused therapy, clinicians explain and explore this with clients. The formulation explores how early life events may have sensitised the individual's threat protection system, leading to the development of safety strategies that can operate automatically, as conditioned and perhaps conflicting responses. For example, some people have well-developed submissive safety strategies. These predispose them to being aware of the rank, status and power of others in relation to themselves, to perceiving themselves as inferior, to being quick to feel socially anxious and uncertain, to engaging in appeasing behaviours, and to avoidance in the face of interpersonal conflict (Gilbert 2005a, 2007). Such strategies can increase their vulnerability to anxiety and depression, lower their self-esteem and interfere with their ability to pursue life goals. So in the evolutionary model, strategies can involve combinations of styles of thinking, behaving and feeling.

Sensitised strategies and phenotypes for threat detection and protection can become major influences on the ways in which a person perceives and navigates their world. The clinician will identify, historically plot and validate the functions and origins of safety strategies (partly to de-shame them) (Linehan 1993; Ogden 2006; Van der Hart 2006; 
Gilbert 2007). In compassion-focused therapy the focus is on understanding the functions of a person's symptoms and difficulties in terms of safety strategies. The first aspects of compassion grow out of this part of the formulation because it helps the client recognise that their pathology and symptoms are 'not their fault' but have often emerged with safety strategies. From here it is possible to begin to develop compassionate and validating reflection on the fact that they needed to develop these safety strategies. This is an approach also well developed in dialectical behavioural therapy (Linehan 1993). In compassion-focused therapy, once individuals stop criticising, condemning and blaming themselves for their symptoms, thoughts or feelings, they are freer to move towards taking responsibility and learning to cope with them.

\section{Drive and excitement}

Animals need emotion and motivational systems that direct them towards important rewards and resources. These include food, sexual opportunities, alliances, nest sites, territories and so forth. So the function of the drive and excitement system in humans (Box 2) is to give us positive feelings that energise and guide us to seek out things (e.g. food, sex, friendships); it is a 'system of desires' that guides us to important life goals (Depue 2005). If we win a competition, pass an exam or get to go out with a desired person, we can have feelings of excitement and pleasure. The feelings associated with this system are linked to arousal, feeling energised and even 'hyped up'. If people take cocaine or amphetamine this is the system they are likely to stimulate. In Buddhist psychology, positive feelings linked to this type of system of achievement and satisfying desires can give us pleasures but not happiness because our pleasure feelings are dependent on acquiring rewards, resources and achievements. In Buddhism happiness comes from cultivating a calm 'non-

BOX 2 The drive system

- This system motivates and directs us to important resources

- It is a source of anticipation and pleasure

- It underpins the development of desires and some goals - both material and those linked to self-esteem (e.g. seeking status or fame)

- It is an activating system highly stimulated by certain drugs

- The positive emotions flowing from this system are often the focus of Western psychology and materialistic cultures striving' mind that is mindful and compassion focused (Dalai Lama 2001).

\section{Interaction of the two systems}

The drive system and the threat protection system can be linked in complex ways, especially when we are driven to avoid negative events, which shows up in thoughts of 'shoulds', 'oughts' and 'musts'. Some individuals pursue status, material possessions and achievement in order to feel safe and avoid feelings of rejection, subordination or inferiority. They may feel the need to prove themselves and to be constantly achieving. Depue $\&$ MorroneStrupinsky (2005) suggest that status-seeking, competitiveness and working to avoid rejection are all linked to the drive system.

There is increasing concern that modern societies overstimulate the drive system (Pani 2000). In depression there is a toning down of the system, creating feelings of loss of positive affect and motivation (Gilbert 2007). Compassion-focused therapy explores the function of the client's goals and how the individual reacts if they stumble or fail to reach them. Is there disappointment or an attack on self or others? Some individuals have a self-identity goal to be 'nice and liked'. The function of this goal is to win affection and avoid rejection and conflict, and if this fails they can become self-critical.

\section{Contentment, soothing and social safeness}

When animals are not having to be attentive to, or deal with, threats and dangers, and they have sufficient resources, they may enter states of contentment (Depue 2005). The positive emotions of the contentment system (Box 3 ) are very different from

B0X 3 The contentment system

- When animals are not threatened and not seeking resources they can become content

- Contentment is associated with a positive 'calm', positive affects and sense of well-being; contentment is not just the absence of threat

- The evolution of attachment behaviour utilised the contentment system, and enabled signals of caring and kindness to have soothing qualities that activate positive affects linked to feelings of well-being, safeness and social-connectedness. This aspect of the system may be called 'social safeness'

- The contentment/social safeness system is internally wired to act as a regulator of the threat protection and drive systems

- Compassion-focused therapy and compassionate mind training are directed at facilitating development of the soothing and social safeness system 
those of the drive system. Contentment is associated with a sense of peacefulness, well-being and quiescence - a state of 'not-seeking'. Contentment is not just the absence of threat or low activity in the threat protection system. Rather, there seems to be a particular system, linked to the opiates, that mediates feelings of well-being and contentment.

Depue \& Morrone-Strupinsky (2005) point out that the contentment system has been significantly developed with the evolution of attachment behaviour. The caring behaviour of the parent, especially physical proximity, has a soothing effect on the infant's physiology. Thus, compassionfocused therapy integrates findings and concepts from attachment research (Bowlby 1969; Gilbert 2005a; Mikulincer 2007). Porges (2007) has written extensively on the way the sympathetic and parasympathetic nervous systems have undergone modifications in mammals to allow them to engage in close interpersonal relationships and soothe each other. The key point is to recognise the importance of caring behaviour in stimulating the soothing and safeness system, and thus soothing overarousal and threat (dis)stress in the individual receiving care. Caring-affiliation operates through an opiate and oxytocin system. Oxytocin is a neurohormone linked to feelings of affiliation, trust and feeling soothed and calmed within relationships (Carter 1998; Uväns-Morberg 1998; Depue 2005; Wang 2005). It is also linked to social affiliation, and there is increasing evidence that it reduces sensitivity, especially to socially threatening stimuli, in fear circuits of the amygdala (Kirsch 2005). I have previously referred to this system as a social safeness system linked to affection and kindness, both of which have soothing properties (Gilbert 1989, 2005a, 2007, 2009).

\section{Balancing the systems}

The neurophysiology and evolutionary concepts outlined in the previous sections are, of course, oversimplifications of complex processes. However, they form a foundation for compassion-focused therapy, in which the therapist's formulations and thoughts are organised around three affect regulation systems (Panksepp 1998; Depue 2005). It is believed that these three systems can become unbalanced, and rebalancing them is one of the goals of therapy.

Heightened sensitivity and overactivity of the threat protection and/or drive systems is a common problem in people with high shame and self-criticism. Individuals find it difficult to feel content or safe within themselves and in interpersonal relationships. According to the principles of compassion-focused therapy, the soothing system is insufficiently accessible to them. There may be many reasons for this. A common one is that it has been understimulated during early life. For example, a person may have received more threats from their parents than soothing. As attachment research has shown, this can leave the individual struggling to feel soothed. In consequence, they may develop anxious or avoidant attachment and interpersonal styles (Mikulincer 2007). Compassion-focused therapy proposes that it is the soothing system that also provides a sense of relief and calming. Individuals who cannot access this system find it hard to feel reassured or calmed/ soothed when they generate (believable) alternative thoughts or engage in helpful behaviours.

\section{The social safeness/soothing system as a focus in the therapy}

Given this developmental, social, evolutionary and neurophysiology model, it is clear why compassionfocused therapy focuses on the development of the social safeness system in the therapy. As we have seen, this system is particularly sensitive to interpersonal cues of social safeness, acceptance and being cared for. It is also key to the regulation of the drive and threat protection systems. Thus, the role of the therapist is to help the client experience safeness in their interactions with them, to tolerate and feel safe with what is explored in the therapy, and to replace self-criticism with self-kindness (Gilbert 2007).

\section{Working compassionately}

Compassion and its components may be defined in many ways. In compassion-focused therapy compassion is understood in terms of specific attributes and skills (Gilbert 1989, 2005a, 2007, 2009). Central to compassion-focused therapy is compassionate mind training: by demonstrating the skills and attributes of compassion (Fig. 2), the therapist instils them in the client. Thus, the client is helped to develop an internal compassionate relationship with themselves to replace the blaming, condemning and self-critical one (Box 4).

\section{The attributes of compassion}

Care for well-being

This requires harnessing the motivation to be caring for the purpose of alleviating distress and facilitating the flourishing and development of the target of the caring.

\section{Sensitivity}

The individual is sensitive to distress and needs, and able to recognise and distinguish the feelings and needs of the target of their caring. 


\section{Sympathy}

Having sympathy involves being emotionally moved by the feelings and distress of the target of their caring. In the therapeutic relationship this means that the client is able to experience the therapist as being emotionally engaged with their story as opposed to being emotionally passive or distant.

\section{Distress tolerance}

Having distress tolerance means being able to contain, stay with and tolerate complex and high levels of emotion, rather than avoid, fearfully divert from, close down, contradict, invalidate or deny them. The client experiences the therapist as able to contain their own emotions and the client's emotions. The therapist is not alarmed, shocked or frightened by the client's emotions or, if they are, they contain it and act in an appropriate way.

\section{Empathy}

Feeling empathy involves working to understand the meanings, functions and origins of another person's inner world so that one can see it from their point of view. Empathy takes effort in a way that sympathy does not. Self-empathy is the ability to stand back from and understand our own thoughts and feelings.

\section{Non-judgement}

Being non-judgemental means not condemning, criticising, shaming or rejecting. However, nonjudgement does not mean non-preference. For example, non-judgement is important in Buddhist psychology where we learn to experience the moment 'as it is'. However, this does not mean we do not have preferences. The Dalai Lama would very much prefer the world to be less cruel and more compassionate. Indeed, these can be highly pursued life goals.

BOX 4 The three aspects of compassionate therapeutic engagement

- The therapist uses the skills and expresses the attributes of compassion

- The client experiences their interaction with the therapist as one that is de-shaming, compassionate and safe; ideally, the client will experience each of the attributes and skills of compassion in, and from, the therapist

- The therapist helps the client to develop compassionate attributes and skills directed at the self

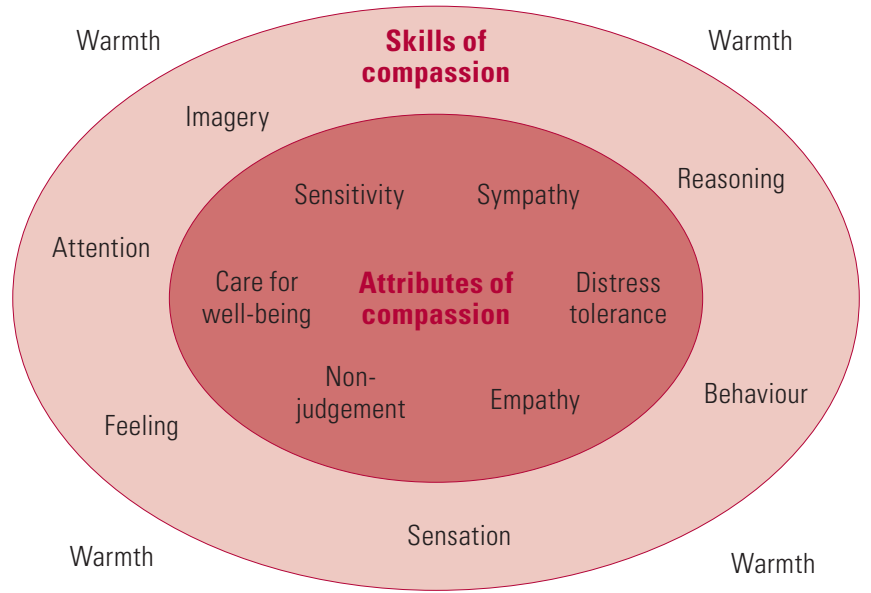

Multimodal compassionate mind training: the key aspects and attributes of compassion (inner ring) and the skills training required to develop them (outer ring). From Gilbert (2009) with permission of Constable and Robinson.

\section{The skills of compassion}

The skills of compassion involve creating feelings of warmth, kindness and support in a range of activities which are (like the attributes of compassion) essentially multimodal and common to many other psychotherapies. People can be taught to engage mindfully with a whole range of therapeutic interventions that focus on thoughts, feelings and behaviours (Mace 2007; Williams 2007). It is particularly important to teach the client to use these skills on themselves. When probed about the emotional textures of their efforts to help themselves, clients with high shame and self-criticism often reveal that they use a cold, bullying or aggressive inner tone to try to change their thoughts and behaviours. Therapists should explore whether clients are trying to force or bully themselves to change, in contrast to being supportive and encouraging of their own efforts to do so.

\section{Compassionate attention}

Compassionate attention is the focusing of our attention in a way that helps and supports us. For example, it may involve remembering times when we were kind to others or others were kind to us, or it might involve compassionate imagery. If we are in conflict with someone, we often overlook the things that we like about them: by refocusing our attention we can regain a more balanced view. The experience of refocusing attention needs to be associated with warmth, support and kindness.

In compassion-focused therapy, the therapist focuses on identifying the client's strengths, positive attributes or skills, such as their courage, kindness to others or previous coping. Clients are 
taught to pay attention and bring to mind their positive qualities, perhaps by revisiting positive memories, and working on those aspects of self.

Therapists can also teach attention-directing exercises linked to the savouring of experiences, to develop the client's appreciation and gratitude. For example, an individual may be encouraged to spend time appreciating the taste of their food, or the colours of the sky or a certain style of music. In many psychopathologies, the threat protection system will be focused on problems and potential difficulties, and individuals can therefore benefit from practising the refocusing of their attention and liberating it from this dominance.

\section{Compassionate reasoning}

Compassionate thinking involves how we reason about the world, ourselves and others. In cognitive therapy (Beck 1979), dialectical behavioural therapy (Linehan 1993) and mentalising (Fonagy 2006) we have a range of interventions to help people develop more balanced reasoning. Compassionfocused therapists build on these interventions but also devote a lot of time to ensuring that clients experience alternative thoughts as kind, supportive and helpful. Logic is not enough: 'evidence' is secondary to the experience of being helped and supported. The process of the therapy itself, whereby the therapist listens warmly, acknowledges and validates clients' emotions and personal meanings, is important for this (Linehan 1993).

Particularly important is how people reason, ruminate and reflect on their current mood states, their future and their sense of self. Shame and self-critical thinking are clearly targets in compassion-focused therapy, but it is important to understand the functions of self-critical thinking and the fears people may have of giving it up. The therapist teaches the problems of certain types of rumination and how to substitute compassionate refocusing in one's thinking.

\section{Compassionate behaviour}

Compassionate behaviour is focused on alleviating distress and facilitating development and growth. This does not mean avoiding engaging with difficult or painful realities or behavioural tasks: courage is important in compassion-focused therapy - indeed, the word encouraging means giving courage. Helping the client to have courage requires clear collaboration on 'the new behaviour' as a compassionate intervention. Exposure work is undertaken in the spirit of compassionate development. So, for example, when the individual has to engage in difficult or frightening behaviour they will try to create an encouraging, warm tone in their minds associated with the supportive thoughts. All the time the client is taught to use warmth, compassion and gentleness as a reference point to move into the more frightening activities. This is a repetition of what would normally happen within a parent-child relationship, where the parent is encouraging and supportive. In compassionfocused therapy the therapist encourages the client to take this orientation to themselves.

Compassion-focused therapy is not just about counteracting threat-based processing or developing different defences such as learning to be assertive rather than submissive: it also seeks to stimulate positive affect processing. Some clients have developed a fear of enjoying themselves or doing nice things for themselves and positive emotions can feel threatening because (in part) they are unfamiliar and the individual feels 'off guard'. Behavioural tasks encouraging exposure to positive emotions can help the client to learn to enjoy experiencing them (fear of compassion is discussed in a separate section below).

Helping people become more process-focused rather than task-focused is also important. Following behavioural traditions, compassionfocused therapy helps people focus on their efforts rather than their results. Thus, clients learn to attend to their effort, no matter how small, and to appreciate that rather than focusing on how far short they fall from their goal. Many high-shame and self-critical clients have never learnt this effort appreciation. Unfortunately, we are living in a society that has become more contemptuous of rewarding effort and in which many believe that 'second is not good enough; who remembers who came second?'

\section{Compassionate imagery}

The technique of using compassionate imagery involves a series of exercises that help the client generate compassionate feelings for themselves. There have been many approaches to developing compassionate feelings by using imagery (Frederick 1999; Leighton 2003; Lee 2005). In compassion-focused therapy, the therapist works to help the client create and explore their image of their 'ideal' of compassion. The client may, for example, explore what their ideal compassionate other might look like, their facial expressions, their voice tones. The therapist guides the client through such imagery exercises, exploring feelings associated with various images. These images are usually fleeting and never clear in the mind, and the therapist advises the client of this. Sometimes clients prefer non-human images such as an 
animal, a tree or a mountain. These too must be imagined as sentient, with specific qualities of wisdom, strength, warmth and non-judgement. Clients often like to imagine that their image has been through similar situations to themselves, as opposed to being some 'higher being' outside of human experience.

There are also exercises related to body postures and imagining oneself as a deeply compassionate person. This is like method acting, when one practises adopting and getting into a particular role. The client imagines themselves as a highly compassionate person and explores their sense of age, facial expressions, body postures, voice tones and styles of thinking. Clients can be encouraged to practise each day at becoming 'the compassionate self', with the appropriate facial expressions, voice tones and ways of thinking.

\section{Compassionate feeling}

Compassionate feeling relates to experiencing compassion from others, for others and for the self. As noted throughout, compassionate feelings are generated in a number of ways, for example via the therapeutic relationship and focused attention, thinking, behaviour and imagery.

\section{Compassionate sensation}

Compassionate sensation refers to the way the therapist helps the client to explore feelings in their bodies when they focus on being compassionate, experiencing compassion from others and being selfcompassionate. By working with and developing these skills, compassion-focused therapy tries to help the client create within themselves feelings of warmth, kindness and support.

\section{The importance of self-compassion}

Compassion-focused therapy follows a behavioural approach in suggesting that internal thoughts and images can act just as external stimuli do, activating different parts of the brain. To demonstrate and explore this with clients the therapist might draw a simple outline of the brain and discuss the effects of both external and internal signals. For example, if we are hungry and we see a lovely meal (external signal) this can start our saliva and stomach acids flowing. Equally, just imagining a lovely meal (internal signal) can have the same physiological effect. If we see something sexual on the television this can stimulate release of hormones from the pituitary to give sexual arousal. But equally we can just fantasise, using our own imagination to stimulate the pituitary to the same effect.

The therapist shares such facts with the client because they provide strong insight into the physiological power of our thoughts, memories and images. The therapist asks the client to consider how they would feel if someone kept putting them down, undermining their confidence, becoming angry with them when things did not go well. Usually, clients are able to identify feelings of anxiety and depression and can recognise that this is because critical signals stimulate their threat protection system. From there the therapist can help the client understand how switching to selfcriticism, focusing/ruminating on self-criticism or bringing to mind times when they have been criticised or put down will stimulate the threat protection system and stress reactions. Indeed, self-criticism can be so constant in a person's mind that it literally harasses them into depressed and anxious states. The clear examples that the therapist has already given of how thoughts and images can stimulate physiological systems enable the client to appreciate the potential power of their own self-criticism.

Time spent clarifying the way our internal thoughts, images and memories can stimulate different physiological systems, using very concrete examples, can pay off in the long term. It also leads straight to the re-focus on compassion. The therapist points out that if we receive understanding, kindness and gentleness from others (in contrast to bullying, criticism and put-down) we feel much more soothed, safe and relieved. This is because those signals stimulate particular systems in the brain; if we did not have those systems we would not experience those feelings. It follows therefore that if we can practise generating these (compassionate) types of thoughts, images and attention, focusing for ourselves we may be able to stimulate and develop the contentment, soothing and safeness system. Indeed, the idea of training the brain to think and feel certain things as a way of stimulating physiological systems is now well established (Begley 2007).

\section{Definitions and the evidence base}

Self-focused compassion as a way of alleviating psychological disorders has gained recent research interest. Definitions of self-compassion, however, vary. The self-esteem cognitive therapists McKay $\&$ Fanning (1992) view self-compassion as understanding, acceptance and forgiveness. From a social psychology and Buddhist tradition, Neff (2003a,b) sees compassion as consisting of three bipolar constructs related to kindness, common humanity and mindfulness. Kindness involves understanding one's difficulties and being kind and warm in the face of failure or set-backs rather than harshly judgemental and self-critical. Common humanity 
involves seeing one's experiences as part of the human condition rather than as personal, isolating and shaming; mindful acceptance involves mindful awareness and acceptance of painful thoughts and feelings rather than trying to force them away or deny them. Compassion-focused therapy focuses on the skills and attributes of compassion as depicted in Fig. 2.

A number of researchers have focused on the differences between self-compassion and self-esteem (Neff 2003a,b, 2007; Gilbert 2005b; Leary 2007). For example, self-esteem tends to increase when we are doing well, succeeding or achieving, whereas self-compassion is important when we are doing badly; self-esteem can give us a sense of favourable comparison with others, where we think in terms of social rank, whereas self-compassion focuses on our similarities and common humanity with others. Crucially, self-compassion focuses on generating a particular type of emotion towards the self that can loosely be called self-warmth or self-kindness. There is limited but increasing research showing the value of training people in self-compassion in both student (Leary 2007) and clinical populations (Gilbert 2006; Mayhew 2008).

\section{Fear of compassion}

Many clients cannot easily access the soothing and social safeness system that underpins compassion. In fact, much of the work in compassion-focused therapy addresses people's fears and resistances to becoming self-compassionate and sometimes to becoming forgiving and compassionate to others.

Attachment theorists suggest that signals of kindness and compassion from another person (especially a therapist) will reactivate the attachment system (Mikulincer 2007). When that happens the (complex and unresolved) memories and feelings within the attachment system may come to the fore. Commonly, for high-shame and self-critical people, particularly those from harsh backgrounds, the beginning of the experience of warmth and kindness in therapy can ignite considerable sadness and grief. This is 'distress calling' and despair as the social safeness system recognises that there may (now) be a response from a caring other. Some clients are overwhelmed or even disassociate from the pain of their grief. The compassion-focused therapist will help to normalise, validate, contain and work with those feelings. In a recent study we found that some people find compassion-focused imagery physiologically stressful (Rockliff 2008). There may be many reasons for this, including the activation of powerful sadness and grief, conditioned emotions of abuse associated with closeness or shame of closeness. These individuals can be among the most difficult to help develop self-compassion, yet once their fears and resistances are worked through, they may also gain greatly from compassionate mind training although we await research evidence for this.

As mentioned above, some clients have negative beliefs about compassion. Self-kindness too can be viewed with suspicion, as being soft, self-indulgent or not deserved. This usually indicates a fear of developing or experiencing self-compassion. Exploration might reveal that the individual is afraid that if they give up self-criticism they will become lazy, unpleasant or unlovable. Some think that they will be punished for self-compassion by 'paying for it later' or having it taken away. The therapist is constantly exploring the interactions between the functions of self-criticism and the fear and avoidance of self-compassion.

In this article I have underlined the importance of compassion in therapy, and pointed out that compassion may also require courage and direct engagement in exposure to threatening and feared situations, feelings or memories. Various therapies address this in different ways (Brewin 2003; Ogden 2006; Van der Hart, 2006; Wheatley, 2007), but they may all be easier to engage in if some compassion work is undertaken before or at the same time as the exposures and reworking. Moreover, compassion is designed to stimulate feelings of safeness, warmth and connectedness that have a direct soothing effect on the threat protection system (e.g. Kirsch, 2005).

\section{Conclusions}

Compassion-focused therapy is an integrated therapy that draws from social, developmental, evolutionary and Buddhist psychology, and neuroscience. It also draws on many other therapeutic models that have developed interventions for specific types of mental health problems. Compassion-focused therapy is in the traditions that seek to build a science of psychotherapy based on research and understanding how our minds work, rather than being focused on a particular school, model or process.

There is a long tradition of compassionfocused interventions in Buddhist psychology and compassion-focused therapy has been profoundly influenced by that tradition. As for all developments in psychotherapy, outcome and process research are key to the future of compassion-focused therapy. Although there are limited data on the value of the approach (Gilbert 2006; Mayhew 2008), there is still much to do to attract funding to research its efficacy.

\section{References}

Andrews B (1998) Shame and childhood abuse. In Shame: Interpersonal Behavior, Psychopathology and Culture (eds P Gilbert, B Andrews): 17690. Oxford University Press. 
Beck AT, Rush AJ, Shaw BF, et al (1979) Cognitive Therapy of Depression. John Wiley \& Sons.

Begley S (2007) Train your Mind: Change your Brain. Ballantine Books.

Bowlby J (1969) Attachment. Vol. 1: Attachment and Loss. Hogarth Press.

Brewin CR (2003) Post-Traumatic Stress Disorder: Malady or Myth. Yale University Press.

Brewin CR (2006) Understanding cognitive behaviour therapy. A retrieval competition account. Behaviour Research and Therapy, 44: $765-84$

Carter CS (1998) Neuroendocrine perspectives on social attachment and love. Psychoneuroendocrinlogy, 23: 779-818.

CaspiA, MoffittTE(2006)Gene-environmentinteractions in psychiatry. Joining forces with neuroscience. Nature Reviews Neuroscience; 7 : 583-90.

Dalai Lama (1995) The Power of Compassion. HarperCollins.

Dalai Lama (2001) An Open Heart: Practising Compassion in Everyday Life (ed N Vreeland). Hodder \& Stoughton.

Davidson RJ, Harrington A (eds) (2002) Visions of Compassion: Western Scientists and Tibetan Buddhists Examine Human Nature. Oxford University Press.

Davidson RJ, Kabat-Zinn J, Schumacher J, et al (2003) Alterations in brain and immune function produced by mindfulness meditation. Psychosomatic Medicine; 65: 564-70.

Depue RA, Morrone-Strupinsky JV (2005) A neurobehavioral model of affiliative bonding. Behavioral and Brain Sciences; 28: 313-95.

Fonagy $\mathrm{P}$, Target M (2006) The mentalization-focused approach to self pathology. Journal of Personality Disorders; 20: 544-76.

Frederick C, McNeal S (1999) Inner Strengths: Contemporary Psychotherapy and Hypnosis for Ego Strengthening. Lawrence Erlbaum Associates.

Gilbert P (1989) Human Nature and Suffering. Lawrence Erlbaum Associates.

Gilbert $P$ (1998) The evolved basis and adaptive functions of cognitive distortions. British Journal of Medical Psychology, 71: 447-64.

Gilbert P (2000) Social mentalities: internal 'social' conflicts and the role of inner warmth and compassion in cognitive therapy. In Genes on the Couch: Explorations in Evolutionary Psychotherapy (eds P Gilbert \& KG Bailey): pp 118-50. Psychology.

Gilbert P (2001) Evolutionary approaches to psychopathology. The role of natural defences. Australian and New Zealand Journal of Psychiatry, 35: $17-27$

Gilbert P (ed) (2005a) Compassion: Conceptualisations, Research and Use in Psychotherapy. Routledge.

Gilbert P, Irons C (2005b) Focused therapies and compassionate mind training for shame and self-attacking. In Compassion: Conceptualisations, Research and Use in Psychotherapy (ed P. Gilbert): 263-325. Routledge.

Gilbert P, Procter S (2006) Compassionate mind training for people with high shame and self-criticism. A pilot study of a group therapy approach. Clinical Psychology and Psychotherapy, 13: 353-79.

Gilbert P (2007) Psychotherapy and Counselling for Depression (3rd edn). Sage.

Gilbert P (2009)The Compassionate Mind: A New Approach to Life's Challenges. Constable-Robinson.

Kaufman G (1989) The Psychology of Shame. Springer.

Kirsch P, Esslinger C, Chen Q, et al (2005) Oxytocin modulates neural circuitry for social cognition and fear in humans. Journal of Neuroscience; 25: 11489-93.

Leary MR, Tate EB, Adams CE, et al (2007) Self-compassion and reactions to unpleasant self-relevant events. The implications of treating oneself kindly. Journal of Personality and Social Psychology, 92: 887-904.

LeDoux J (1998) The Emotional Brain. Weidenfeld and Nicolson.
Lee DA (2005) The perfect nurturer: a model to develop a compassionate mind within the context of cognitive therapy. In Compassion: Conceptualisations, Research and use in Psychotherapy (ed P Gilbert): 326-51. Brunner-Routledge.

Leighton TD (2003) Faces of Compassion: Classic Bodhisattva Archetypes and their Modern Expression. Wisdom Publications.

Linehan M (1993) Cognitive Behavioral Treatment of Borderline Personality Disorder. Guilford Press.

Lutz A, Brefczynski-Lewis J, Johnstone, T, et al (2008) Regulation of the theme neural circuitry of emotion by compassion meditation: effects of the meditative expertise. Public Library of Science; 3: 1-5.

Mace C (2007) Mindfulness in psychotherapy: an introduction. Advances in Psychiatric Treatment, 13: 147-54.

Marks IM (1987) Fears, Phobias and Rituals: Panic, Anxiety and their Disorders. Oxford University Press.

Mayhew S, Gilbert P (2008) Compassionate mind training with people who hear malevolent voices. A case series report. Clinical Psychology and Psychotherapy, 15: 113-38.

McKay M, Fanning P (1992) Self-Esteem: A Proven Program of Cognitive Techniques for Assessing, Improving, and Maintaining Your Self-Esteem (2nd edn). New Harbinger Publishers.

Mikulincer M, Shaver PR (2007) Attachment in Adulthood: Structure, Dynamics, and Change. Guilford Press.

Neff KD (2003a) Self-compassion. An alternative conceptualization of a healthy attitude toward oneself. Self and Identity, 2: 85-102.

Neff KD (2003b) The development and validation of a scale to measure self-compassion. Self and Identity, 2: 223-50.

Neff KD, Rude SS, Kirkpatrick KL (2007) An examination of selfcompassion in relation to positive psychological functioning and personality traits. Journal of Research in Personality, 41: 908-16.

Ogden P, Minton K, Pain C (2006) Trauma and the Body: A Sensorimotor Approach to Psychotherapy. Norton.

Pani L (2000) Is there an evolutionary mismatch between the normal physiology of the human dopaminergic system and current environmental conditions in industrialized countries? Molecular Psychiatry, 5 467-75.

Panksepp J (1998) Affective Neuroscience. Oxford University Press.

Porges SW (2007) The polyvagal perspective. Biological Psychology, 74: 116-43.

Rector NA, Bagby RM, Segal ZV, et al (2000) Self-criticism and dependency in depressed patients treated with cognitive therapy or pharmacotherapy. Cognitive Therapy and Research; 24: 571-84.

Rockliff H, Gilbert P, McEwan K, et al (2008) A pilot exploration of heart rate variability and salivary cortisol responses to compassion-focused imagery. Journal of Clinical Neuropsychiatry, 5: 132-9.

Rosen JB, Schulkin J (1998) From normal fear to pathological anxiety. Psychological Bulletin; 105: 325-50.

Schore AN (1998) Early shame experiences and infant brain development. In Shame: Interpersonal Behavior, Psychopathology and Culture (eds P Gilbert, B Andrews): 57-77. Oxford University Press.

Uväns-Morberg K (1998) Oxytocin may mediate the benefits of positive social interaction and emotions. Psychoneuroendocrinology, 23: 81935.

Van der Hart 0, Nijenhuis ERS. Steele K (2006) The Haunted Self: Structural Dissociation and the Treatment of Chronic Traumatization. Norton.

Wang S (2005) A conceptual framework for integrating research related to the physiology of compassion and the wisdom of Buddhist teachings. In Compassion: Conceptualisations, Research and Use in Psychotherapy (ed P Gilbert): 75-120. Brunner-Routledge.

Wheatley J, Brewin CR, Patel T, et al (2007) "I'Il believe it when I see it": imagery re-scripting of intrusive sensory memories. Journal of Behavior Therapy and Experimental Psychiatry, 39: 371-85.

Williams M, Teasdale J, Segal, Z, et al (2007) The Mindful Way Through Depression: Freeing Yourself from Chronic Unhappiness. Guilford Press.

\begin{tabular}{lllll}
\multicolumn{4}{l}{ MCO answers } \\
1 & 2 & 3 & 4 & 5 \\
af & af & af & af & af \\
bt & bt & bf & bt & bt \\
cf & cf & ct & cf & cf \\
df & df & df & df & df \\
ef & ef & ef & ef & ef
\end{tabular}




\section{MCOs}

1 Compassion-focused therapy was developed for:

a obsessive-compulsive disorder

b shame and self-criticism

c fear of flying

d depersonalisation

e hypomania.

\section{Compassion-focused therapy is derived} from:

a Freud's theory of the Oedipal complex

b evolutionary theory

c forensic psychology

$\mathrm{d}$ anxiety management

e studies of anger management.
3 Formulation in compassion-focused therapy is focused on:

a identifying maladaptive schema

b revealing unconscious conflicts

c linking background fears to safety strategies

d only current problems

e identifying behavioural deficits.

\section{Compassion-focused therapy teaches} people to:

a avoid things they find difficult

b practise generating feelings of warmth for themselves

c find ways to threaten their internal self-critic

d rely on logic to regulate emotion

e always express their feelings.
5 Compassion-focused therapy uses analogies of:

a every cloud has a silver lining

b physiotherapy for the mind

c disassociating oneself from difficulties

$d$ the ends justifying the means

e all's well that ends well. 